\title{
Exploring Islamic Based Caring Practice in Intensive Care Unit: A Qualitative Study
}

\author{
Suhartini Ismail ${ }^{1}$, Urai Hatthakit ${ }^{2}$, Praneed Songwathana ${ }^{3}$ \\ ${ }^{1}$ Department of Nursing, Emergency and Critical Care Division, Faculty of Medicine, Diponegoro \\ University, Semarang, Indonesia \\ ${ }^{2}$ Associate Professor, Administrative Nursing Department, Faculty of Nursing, Prince of Songkla \\ University, Thailand \\ ${ }^{3}$ Associate Professor, Surgical Nursing Department, Faculty of Nursing, Prince of Songkla University, \\ Thailand \\ Corresponding Author: Suhartini (suhartini.ismail@fk.undip.ac.id)
}

\begin{abstract}
Background: Even the advanced technology of modalities in intensive care unit (ICU) has been required a lot, it is important to date that nurses understand the Islamic faithbased healing in the holistic nursing care.

Purpose: A phenomenological approach was conducted to describe the caring behaviors based on Islam for the patients in ICU from the perspective of nurses and patients' family.

Methods: Fourteen ICU nurses and 10 families participated in the study. In-depth interviews with nurses and families were conducted. The data were analyzed using inductive content analysis.

Results: The findings revealed that Islamic-based caring in ICU was connecting to God (Allah), being present with patients and family, and nurses were an instrument to assist the patients and family to be faith in God. In addition, some barriers regarding Islamic based caring practice were presented, such as limited of knowledge and skill to provide Islamic based caring.

Conclusion: Islamic based caring is very important in practicing the balance of body, mind, and spirit. It is suggested that the nurses are applying Islamic based caring improve the quality of care related to cultural care. The next investigation is needed to measure the nurse caring behavior based on Islamic perspective.
\end{abstract}

Keywords: Caring; Indonesian nurse; Intensive Care Unit; Islamic based caring

\section{BACKGROUND}

The nature of the Intensive Care Unit (ICU) is as a closed-unit with strict visiting hours and uses equipment of a high technological standard. It may constitute the difficulties and conflicts related to the caring situation, and reflects a different aspect of caring compare with the opened unit environment (Pryzby, 2005). In the ICU environment, the patients and families may experience lack of humanization approach related to care provision, decision making, and the physical design of the environment (Brett, 2002; Pryzby, 2005). Lack of humanization in the ICU may be caused by isolation of unit, emotional distress, and communication barriers (Duldt-Battey, 2004). Therefore, caring 
in ICU does not focus on the technology but also emphasizes on recognizing the patient's characteristics and addressing the human being with dignity and respect.

Caring is an essence of nursing, and it exists in the culture. Caring is humanistic, spiritual, and an ethical phenomenon, which integrates knowledge of the sociocultural environment (Davidson, Ray, \& Turkel, 2011). However, to be effective, caring must be applicable and culturally relevant (Leininger, 1988). For example, a study of caring for Islamic patients in Saudi Arabia, the caring by nurses' reflected in three aspects include family, cultural, and nurse-patient relationship. It is reflected that the importance of family roles and culture in providing care (Halligan, 2006). Also, caring integrates with environment, culture, and others people in the boundary of relationship.

Under the Islamic concept and practice, when a person is sick, he or she will seek both medical and non-medical treatment. A non-medical treatment in particular related to God is used to enhance his or her spirituality and hoped to get well (Rassool, 2000; Rassool, 2004). The illness is one way of Allah to remove the sin (Ibrahim \& Dykeman, 2011) in the Islamic faith. The Islamic faith or belief in God is a holistic direction for a way of life to promote health and harmony of body, mind, and spirit (Ohm, 2003). Muslims have consistently believed in the Divine and thought positively about the illness, even if the person is facing a critical illness (Bloomer \& Al-Mutair, 2013). Therefore, critical care nurses should address not only physiological care but also care for the psychosocial (care of mind), and spiritual (care of the spirit) domains (Smith, 2006).

However, Islamic caring in previous nursing literature was mainly addressed the caring from nurses' perspectives and still limited to others' perspectives. Nurses should actively update the existing information regarding how caring is perceived, assessed and implemented in reality. A previous study by Barolia and Karmaliani (2008) has suggested developing the Islamic based caring which may provide a better quality of care and enhance positive experiences for the patients. Therefore, this study emphasizes on Islamic based caring, that is congruent with Indonesia culture with the majority of Muslim population.

\section{OBJECTIVE}

This study aimed to describe caring behaviors based on Islam for the patients in ICU from the perspective of nurses and patients' family.

\section{METHODS}

Design of this study was a qualitative study. This approach was regarded to the person involved in the caring practice. The qualitative approach is valuable in exploring Islamic based caring practice for critically ill patients in Indonesia. This study was undertaken in an ICU of a public hospital in Semarang, Indonesia. Data were gathered from in-depth-interview with 14 nurses and 10 patient's families using purposive sampling with inclusion criteria. The nurses' criteria were between ages of 20 and 50 years, male and female, had working experiences of at least 2 years in ICU, and had graduated from Diploma 3 or bachelor degree. For families, the criteria were between the age of 18-60 years, males, and females, and were the primary caregiver for the 
patients. In-depth interviews were conducted in the discussion room in ICU of the hospital. The important demographic information was collected using demographic form. The informed consent was given to the participants to explain the ethical consideration in the study. The time duration of the interview was between 1 to 1.5 hours. A tape recorder and camera during data collection were used to record the interviews.

The content analysis guided by Elo and Kyngäs (2008) was used to analyze the data. To ensure the trustworthiness, the researcher followed the inductive content analysis process. Started with open coding, all notes and heading were written in the text while reading it. The written material was read thoroughly, and as many headings as necessary were written down in the margins to describe all aspects of the content. The headings were gathered from the margins on to coding sheets, and categories were freely generated. After open coding, the list of categories was grouped under higher order headings and collapsed the similarly into broader higher-order categories. Finally, major themes were identified through interpretation as inductive content analysis. The use of quotation was presented in the findings of the study to support the themes.

The trustworthiness of this study was maintained by emphasizing four methods: credibility, dependability, transferability, and conformability. Credibility was gained by member checking and triangulation. The member checking was used to get the feedback from the participants, their reaction to the data and findings, and their response to the researcher's interpretation of the data. Member checking was given to the participants after the researchers transcribed verbatim and analyzed the data. Triangulation of the data was gained by comparing various data from participants with the caring theory and Islamic concept. Dependability was established by asking an outside researcher to conduct an inquiry audit of the research study. An inquiry audit involves a researcher outside of the data collection and data analysis, and the results of the research study. This was done to confirm the accuracy of the findings and to ensure the findings are supported by the data collected. All interpretations and conclusions were examined to determine whether they are supported by the data. Transferability was achieved by providing adequate information of the participants, the setting, and the context of the study.

The ethical consideration of the study was approved by the Institutional Research Board of Faculty of Nursing, Prince of Songkla University, and the Ethical Committee in the hospital. The participants were informed about the research objectives, right, and benefits. They were asked for their voluntary participation. They could refuse anytime without any negative consequences. The information gathered from participants was kept confidentially. The data were recorded and transcribed using a pseudonym to keep anonymity.

\section{RESULTS}

\section{Demographic characteristics of the participants}

A total of 24 participants were enrolled in this study, including nurses $(n=14)$ and patients' families $(n=10)$. For nurse participants, their ages ranged between $23-44$ years $(\mathrm{M} \pm \mathrm{SD}=29.33 \pm 5.49)$, female $(n=7)$ and male $(n=7)$. A half of them had earned a 
bachelor degree and had working experience of less than 5 years. The family members who participated in this study were patient's wife $(n=4)$, patient's husband $(n=5)$, patient's daughter $(n=2)$, patient's mother $(n=2)$, and patient's son $(n=1)$.

\section{Exploring Islamic based caring for critically ill patients \\ Giving attention intensively to the patients as being with the family}

The nurses paid their attention to the patients by being with them both physically and mentally, as they were like brothers or sisters. Islam teaches the followers between one to another like a family. The nurse was the main health care provider who was with the patients and families and provided care for them in the crisis, as stated by the nurses and families:

\footnotetext{
"Caring is one of the Islamic values, as we care other Muslims. Prophet Muhammad said Muslim is like brothers and sisters". (Nurse I)

"Through a sense of sincere, then the soul will be calm and peaceful....I am with the patients in order to meet their needs in dealing with the crisis". (Nurse E)

"We need the nurses who are with us in dealing with a crisis, as we know the nurses stayed for us for several hours in ICU." (Family 10)
}

\section{Creating a sense of peace in body, mind, and spirit via Allah}

The nurses described their caring in Islam as related to a religious belief regarding in terms of creating a sense of peace in body, mind, and spirit via Allah. Patients and families oriented themselves to follow the Islamic rules when they were dealing with critical conditions. In dealing with the critical situation, it was recognized as essential to practice and demonstrate nurse's caring. The nurses provided Islamic nursing interventions by giving advice and assisting the patients and families to follow the Islamic faith, as Muslim obligation to Al Quran and Hadiths in their daily life such as praying, respecting to Allah's will, and Dua.

"We like the nurse who is remembering Allah in the working procedure. For instance, saying 'Bismillah' before doing an intervention, and say "Alhamdulillah" after finish it. Therefore, we feel a sense of peace in our mind and get the spirit in dealing with the crisis". (Family 10)

"To give a sense of peace for patients and families, I reminded the patients and families to do praying and accomplish 'Shalat' to ask recovery and help from Allah." (Nurse U)

"I lead myself, and my patient said 'Bismillah' in term of Islamic thought when I conduct a nursing procedure." Saying "Bismillah" means we mentioned Allah in doing our work anytime, and the patients would receive protection from Allah, as we did not forget Him. In doing so, I felt Allah saw and protected me in working, and the patients felt a sense of peace as I included them to mention Allah saying the words". (Nurse B)

The participants gained an awareness of the ramifications of the Islamic faith. During the time of sickness and suffering in ICU, the nurses assisted patients. Three nurses stated: 
"There was no cure for every disease, and we have to show gratitude for our circumstances. If we do patients' attitude, then God will always to be with us. It is also one of the signs of our faith in the Lord (Allah, SWT)". (Nurse A)

"Prophet Muhammad taught us that God is the most compassionate and merciful so that whatever our circumstances and how we present it all is set up by God and we have to accept the situation." (Nurse T)

"I was inviting patient's families to perform praying together with patients every morning. It is encouraging patients and families to meet their spiritual need. I invite my patients to be thankful (bersyukur) for what God has given because Allah is listening, loving, and evermore caring. Lastly, the patient will feel calm". (Nurse D)

\section{Opening a relationship with the patients and their families}

Patients addressed that caring is essential. The openness of relationship for patients and families was necessary to explore the patient's condition. Being open with patient and family could be shown when nurses listened and communicated. In Islam, openness means an acceptance of patient and family as our close family. The nurse was humble in taking care of the patients in the critical situation and supported the families to face the situation by trusting to Allah. Nurses and families shared their similar views about being open to a relationship.

"The nurse who takes care of my mom is nice. She is available to listen and help patients and families. My mom very appreciated her care. I like the nurses who are opened in their relationship with patients as they help patients to feel safe, comfortable, and close". (Family 5)

"Based on my experience, caring helps heal patients such as sharing a willingness to help compassion and empathy for their suffering, by being opened in our relationship with the patients and their family." (Nurse C)

"The patient is as a family. As a family, I understand the patient what they hoped in the current situation even the patient could not express it. The nurse should be patient and give them comfort, and paid attention to the patient in the first priority of responsibility." (Nurse A)

\section{Being present with the patient and their family for supporting their faith}

Being present with the patients and their families was generally perceived as important. Participants described not only on the physical presence of nurses in nursing care but also on psychological presence. Being present in the Islamic teaching means the nurses were being with the patients and supported them including the time, touch, and talk. It was described by the families as below:

"Presence doesn't take more of the nurses' time. It makes every moment of connection with us (patients and families) precious". (Family 1)

"We feel the nurses' attention here. They accepted us to be with in facing the critical situation. The nurses touched, rubbed hands, and talked with us even the patients cannot communicate verbally". (Family 2) 


\section{Guiding and mediating the patients and families to connect to Allah.}

The Muslim patients with critical illness could not do the Islamic ritual as their obligation every time such as Shalah. Shalah five times a day is an obligation for Muslim, but this may be limited to patients in ICU. The nurse was as a mediator to facilitate the patients to do the Islamic ritual as well as for their families. The statements from a family as follows.

"The nurses in the ICU help and guide us to stay connected with Allah. They were willing to pray together with us. They provided "Al Quran, Surah Yassin, and tasbih" for us to stay connected with Allah. We feel calm, sincere, and patient to face the condition". (Family 5)

\section{Nurses' barriers to performing Islamic based caring practice in ICU}

Islamic based caring practice in the ICU was expected to be performed. However, nurse participants reflected some barriers.

\section{Limited learning resources and role model in Islamic based caring}

In this study, the nurses had insufficient knowledge on Islamic based caring, and there were limited resources to learn about it. Also, there was no a role model to give an example and inspired them to provide Islamic based caring. The evidence was obtained from the nurses' experience:

"We consider, the nurses and the head nurse have not enough knowledge in Islamic based caring for the critically ill patients. The hospital has prepared Muslim cleric to provide appropriate spiritual care for the patients and families". (Nurse $\mathrm{H}$ )

"We don't have the nurses who can give us role model in caring for the patient. Some of the nurses here are young nurses; we certainly need role modeling from our colleagues to inspire us in Islamic based caring. I myself also need to learn more to be a role model for my nursing staff”. (Nurse T).

\section{Lack of time to offer the Islamic based caring due to heavy workload}

Some nurses in the ICU felt lack of time to offer Islamic based caring. They paid more attention to treat the patients' disease and safe life, rather than to offer the spiritual care. The spiritual care was perceived as a part of holistic care, but nurses in ICU were unable to perform it due to their heavy workload. Some nurses reflected their experience:

"I do not have spare time to offer the Islamic based caring. I only suggested the patients and families pray as needed to release their tension". (Nurse A)

"In daily practice, I remembered to pay attention to spiritual care related to the patients' and families' belief in Islam. However, I forgot them to provide it due to heavy workload". (Nurse R)

\section{DISCUSSION}

The participants in this study perceived that Islamic based caring is essential in dealing with the critical situation in ICU. The nurses in particular view that Islamic based caring can help the critically ill patients to stay connected with Allah. Nurses can be "active 
person" when the patients and families were experienced in critical conditions. Therefore, the nurse in this study should understand their perspective in Islamic concepts in applying caring to the Muslim patients and their families.

The participants described that the Islamic based caring is giving intensive attention to the patient as like as a family, and creating a sense of peace in body, mind, and spirit via Allah. This is consistent with prior studies that paying attention to the patients and families can support the healing process; it works as well as bio-psycho-social-spiritual healing (Bergdahl, Benzein, Ternestedt, \& Andershed, 2011; Mensah \& Jankowski, 2012). Muslims also considered that illness was a part of life. This was the nature of our lives; we should in toil and struggle when the times of difficulties and ease. It is a life full of tests, as Allah says: "And certainly, We shall test you with something of fear, hunger, loss of wealth, lives and fruits, but give glad tidings to as-Saabirin (be patient, etc.)." (Al Quran 2:155). As a result, patients need to be persistent to gain their inner power to survive the suffering in ICU.

The patient's crisis has been found to affect of nurse-patient relationship (Barnard, 2000; Browne \& Cook, 2011). Therefore, the nurses in this study perceived the openness of relationship with the patients and families by being with them is important. Several ways to be close to the patients and families, such as the nurses accompany the families during visiting time. The Islamic based caring was perceived as a means to carry out the responsibility aside for the time being with the patients, such as touching, holding patient's hand, observing, and listening. Touching and holding patient's hand were applied as a gesture of caring while observing was applied as a professional responsibility to observe all the patient's aspect. Listening was performed to understand the patients' and family needs clearly. It appears that the nurses enhanced their relationships by being with the patients and families as their needs. It would help them feel a connectedness with the nurses. Having a supportive relationship when caring for the patients and their families based on the presence, has shown a positive influence on the nurses-patients relationship (Nagel, Pomerleau, \& Penner, 2013).

In Muslim society, scholars suggested that caring should be focused not only on the physical aspect of a human being but should also be concerned with the interrelationship between the multiple dimensions of persons too. A human being has a soul and an intellect that require moral, ethical, and intellectual care to stay healthy (Rassool, 2000). Muslims believe that Islam teachings bear on all aspects of life, and they strive to keep Allah at the center of their consciousness, intentions, and actions (Power, 2007; Stefan, 2010). Similarly, Hyder (2003) suggested that the nurses should perform an accurate assessment and integrate the patient's religious and spiritual beliefs interventions in nursing care to Muslim patients.

In this study, the participants stated that Shalah is a ritual prayer for Muslims that should be done even the patient could not stand up as long as it meets the rules of purity. Muslim scholars agreed that even someone who has the physical limitation or in sickness condition still has a duty to perform the Shalah (Dewiyanti \& Kusuma, 2012). Shalah makes the Muslim feel a connection with Allah. Under the Muslim conception, reminding and promoting Shalah is represented as a spiritual care. Consistent with 
spiritual care, it affected human life and manifested in conjunction with self, others, and the universe and God (Dossey, Keegan, \& Guzzetta, 2005).

Seeking treatment options for the critically ill patients available to Muslim patient may include modern treatment and spiritual healing. A seeking for modern treatment was an effort to get help from professional care while a healing for Muslim patients was a hope and heal by God (Allah). Patients might carry out more righteous deeds and improve the connection with God (Abu Raiya, Pargament, Mahoney, \& Stein, 2008). Moreover, the positive thinking to Allah could be provided and sought as a remedy to help the patients (Hoseini, Alhani, Khosro-panah, \& Behjatpour, 2013; Ohm, 2003). The positive thinking to Allah implied that the patients and families should be sincere to keep struggle in dealing with a crisis.

The nurses became a religious person to mediate the patients and families' connection with Allah. The nurses helped the patients and families to maintain their faith. This was similar to a prior study which noted that religion was a means to express the spirituality (Sartori, 2010). A higher power of Allah could arouse hope, seek remediation, and exceed physical and conscious constraints (Ismail \& Hatthakit, 2015). In other words, the Islamic faith teaches the followers for the remembrance of Allah. The remembrance of Allah is recommended as a sense of peace in this life and the hereafter. It is also the sense of comfort, even in the crisis.

However, the participants stated some barriers in applying the Islamic based caring. They feel something missing regard to Islamic views when they want to practice it. It is considered a missing from the nurses' knowledge since the nurses have other responsibilities in nursing practice. They also have no remodeling who can provide and inspire them the Islamic based caring in their daily practice. It is consistent with a previous study that some barriers in caring practices included lack knowledge and caring behavior (Rushton, 2014). It is suggested that Islamic based caring should be added to the spiritual care competency by the professional nurses.

\section{CONCLUSION AND IMPLICATION}

The critical care nurse must recognize that Islamic perspectives on caring begin as a new trend in nursing scholars. To provide optimal Islamic based caring, the critical care nurses must take into consideration each of physical, psychological, and spiritual aspects of the patients and their family members. Islamic based caring in nursing field can reap positive benefits for the patients, families, as well as the healthcare providers. Islamic based caring pointed out the spiritual based on taking care of the patients and their family in this study. The participants were in a belief that the highest power to get healing is only from the Oneness of God (Allah) instead of the seeking of treatment from professional health care. Therefore, the Islamic based caring deserves to be given attention not only because of its medical treatment, but also because of its ability to bring the nurses, patients, and families in deeper relationships with Allah to create a sense of peace and power of healing. 


\section{ACKNOWLEDGEMENT}

The researchers would like to acknowledge the scholarship committee of the Directorate General of the Ministry of Research, Technology and Higher Education, Republic of Indonesia. The researchers also extend their gratitude to the dean of the graduate school in Prince of Songkla University who has given a partial support to finish this study.

\section{REFERENCES}

Abu Raiya, H., Pargament, K. I., Mahoney, A., \& Stein, C. (2008). A Psychological Measure of Islamic Religiousness: Development and Evidence for Reliability and Validity. (18), Routledge. Retrieved from http://www.tandfonline.com/doi/abs/10.1080/10508610802229270

Barnard, A. (2000). Alteration to will as an experience of technology and nursing. Journal of Advanced Nursing, 31(5), 1136-1144. doi:10.1111/j.13652648.2000.tb03460.x

Barolia, R., \& Karmaliani, R. (2008). Caring in nursing from an Islamic Perspective: A grounded theory approach. International Journal for Human Caring, 13(1), 5563.

Bergdahl, E., Benzein, E., Ternestedt, B.-M., \& Andershed, B. (2011). Development of nurses' abilities to reflect on how to create good caring relationships with patients in palliative care: an action research approach. Nursing Inquiry, 18(2), 111-122.

Bloomer, M. J., \& Al-Mutair, A. (2013). Ensuring cultural sensitivity for Muslim patients in the Australian ICU: Considerations for care. Australian Critical Care, 26(4), 193-196. doi:http://dx.doi.org/10.1016/j.aucc.2013.04.003

Brett, A. S. (2002). Problems in caring for critically and terminally ill patients: Perspectives of physicians and nurses. HEC Forum, 14(2), 132-147.

Browne, M., \& Cook, P. (2011). Inappropriate trust in technology: Implications for critical care nurses. Nursing in Critical Care, 16(2), 92-98. doi:10.1111/j.14785153.2010.00407.x

Davidson, A. W., Ray, M. A., \& Turkel, M. C. (2011). Nursing, caring and complexity science. New York: USA: Springer.

Dewiyanti, D., \& Kusuma, H. E. (2012). Spaces for Muslims Spiritual Meanings. Procedia - Social and Behavioral Sciences, 50(0), 969-978. doi:http://dx.doi.org/10.1016/j.sbspro.2012.08.098

Dossey, B. M., Keegan, L., \& Guzzetta, C. E. (2005). Holistic nursing: A handbook for practice (4 ed.). Mississauga, Canada: Jones and Bartlett.

Duldt-Battey, B. W. (2004). Humanism, nursing, communication, and holistic care: A position paper. 1-49. htpp://www.samuelmerritt.edu/depts/nursing/duldt

Elo, S., \& Kyngäs, H. (2008). The qualitative content analysis process. Journal of Advanced Nursing, 62(1), 107-115. doi:10.1111/j.1365-2648.2007.04569.x

Halligan, P. (2006). Caring for patients of Islamic denomination: Critical care nurses' experiences in Saudi Arabia. Journal of Clinical Nursing, 15, 1565-1573.

Hoseini, A. S. S., Alhani, F., Khosro-panah, A.-h., \& Behjatpour, A.-k. (2013). A concept analysis of nursing based on Islamic Sources: Seeking remedy. International Journal of Nursing Knowledge, Article in Press, 1-8. doi:10.1111/j.2047-3095.2013.01244.X

Hyder, G. (2003). Care of the Muslim patient. Australian Nursing Journal, 11(2), 1-3. 
Ibrahim, F. A., \& Dykeman, C. (2011). Counseling Muslim Americans: Cultural and spiritual assessments. Journal of Counseling \& Development, 89, 389-396.

Ismail, S., \& Hatthakit, U. (2015). The Development of Islamic Based Caring Model for Critically Ill Patients (Doctoral Dissertation). Prince of Songkla University, Hatyai, Thailand.

Leininger, M. M. (1988). Caring an essential human need: Proceedings of the three national caring conferences. Detroit, Michigan: Wayne State University.

Mensah, K., \& Jankowski, S. (2012). Care of the critically ill patient. Surgery (Oxford), 30(5), 232-237. doi:10.1016/j.mpsur.2012.02.003

Nagel, D. A., Pomerleau, S. G., \& Penner, J. L. (2013). Knowing, Caring, and Telehealth Technology: "Going the Distance" in Nursing Practice. Journal of Holistic Nursing, 31(2), 104-112. doi:10.1177/0898010112465357

Ohm, R. (2003). The African American experience in the Islamic faith. Public Health Nursing, 20(6), 478-486. doi:10.1046/j.1525-1446.2003.20608.x

Power, C. (2007). Baring our selves. Retrieved from http://www.time.com/time/magazine/article/0,9171,1668236,00.html

Pryzby, B. J. (2005). Effects of nurse caring behaviours on family stress responses in critical care. Intensive and Critical Care Nursing, 21(1), 16-23. doi:10.1016/j.iccn.2004.06.008

Rassool, G. H. (2000). The crescent and Islam: healing, nursing, and the spiritual dimension. Some considerations towards an understanding of the Islamic perspectives on caring. Journal of Advanced Nursing, 32(6), 1476-1484. doi:10.1046/j.1365-2648.2000.01614.x

Rassool, G. H. (2004). Commentary: An Islamic perspective. Journal of Advanced Nursing, $\quad 46(3), \quad 281-283 . \quad$ doi:http://dx.doi.org/10.1111/j.13652648.2004.02987_4.x

Rushton, L. (2014). What are the barriers to spiritual care in a hospital setting?. British Journal of Nursing, 23(7), 370-374. doi: 10.12968/bjon.2014.23.7.370.

Sartori, P. (2010). Spirituality 1: should spiritual and religious beliefs be part of patient care? Nurs Times, 106(28), 14-17.

Smith, A. R. (2006). Using the Synergy Model to provide spiritual nursing care in critical care settings. Critical Care Nurse, 26(4), 41-47.

Stefan, M. (2010). Islamic Beliefs and Practices. New York, NY: Britania Educational. 